\title{
Effect of Biochanin A on Serum Visfatin Level of Streptozocin-Induced Diabetic Rats
}

\author{
Reza Azizi ${ }^{1}$; Mohamad Taghi Goodarzi ${ }^{2}$; Zahra Salemi ${ }^{1,3, *}$ \\ ${ }^{1}$ Department of Biochemistry, Arak University of Medical Sciences, Arak, IR Iran \\ ${ }_{2}^{2}$ Molecular Medicine Research Center, Hamadan University of Medical Sciences, Hamadan, IR Iran \\ ${ }^{3}$ Molecular and Medicine Research Center, Arak University of Medical Sciences, Arak, IR Iran \\ *Corresponding Author: Zahra Salemi, Department of Biochemistry, Arak University of Medical Sciences, Arak, IR Iran. Tel: +98-9183645842, Fax: +98-8634173529, E-mail: Dr.zsalemi@ \\ arakmu.ac.ir
}

Received: October 14, 2013; Revised: December 18, 2013; Accepted: January 15, 2014

\begin{abstract}
Background: Bioflavonoids are well known for their multi directional biologic activity including antidiabetic effect. It has been demonstrated that flavonoids can act as insulin secretagogue or insulin mimetic agents.

Objectives: This experimental study was designed in Arak University of Medical Sciences, Arak, Iran, to investigate the effects of biochanin A (a bioflavonoid) on fasting blood glucose (FBG), body weight, glycosylated hemoglobin $\left(\mathrm{HbA}_{1} \mathrm{c}\right)$, lipid profile, serum enzymes, and visfatin of streptozocin-induced diabetic rats.

Patients and Methods: We used 24 male Wistar rats and randomly allocated them to four groups of six rats. One group was randomly assigned as control and diabetes was induced in three other groups by administration of streptozocin (35 mg/kg of body weight) intraperitoneally. The groups received the following treatments: group 1(control), 5\% DMSO; group 2 (diabetic control), 0.5\% DMSO; and group 3 and 4, respectively 10 and $15 \mathrm{mg} / \mathrm{kg}$ biochanin A for 30 days. Body weight and biochemical parameters including FBG, $\mathrm{HbA} \mathrm{A}_{1}$, lipid profile, aspartate aminotransferase (AST), alanine aminotransferase (ALT), alkaline phosphatase (ALP), and visfatin were measured in all rats.

Results: FBG level was significantly reduced in treated diabetic rats (139.8 \pm 9.3 and $206 \pm 11 \mathrm{mg} / \mathrm{dL}$ in groups 3 and 4, respectively) in comparison to the diabetic control $(295.1 \pm 14 \mathrm{mg} / \mathrm{dL})(\mathrm{P}<0.05)$. Administration of biochanin A significantly decreased $\mathrm{HbA}_{1} \mathrm{c}$ in group $3(6.66 \pm 0.33)$ and group $4(7.11 \pm 0.31)$ in comparison to the diabetic control group $(8.26 \pm 0.44)(P<0.05)$. Levels of serum visfatin were improved to near normal levels in the treated rats $(249 \pm 35.5$ and $161.33 \pm 13.07$ in groups 3 and 4 , respectively) in comparison to the diabetic control $(302.17 \pm 19.4)(\mathrm{P}<0.05)$. Furthermore, biochanin A showed a protective effect against weight loss in diabetic rats $(\mathrm{P}<0.05)$. In treated rats, serum total cholesterol, triglyceride, and low-density lipoprotein cholesterol (LDL-c) were significantly decreased and highdensity lipoprotein (HDL-c) was increased in comparison with the diabetic control group. In addition, biochanin A restored the altered plasma enzymes (AST, ALT, and ALP) activities to near normal. Histopathologic examination of the pancreas also indicated that biochanin A had protective effects on $\beta$-cells in streptozocin-induced diabetic rats.

Conclusions: This study demonstrated that biochanin A possessed hypoglycemic and antilipemic activities and could increase visfatin expression, which suggests its beneficial effect in the treatment of diabetes.
\end{abstract}

Keywords:Visfatin; Biochanin A; Diabetic Rats

\section{Background}

Diabetes mellitus is a metabolic disorder with the origins as old as mankind and its incidence is considered to be high worldwide (1). It is characterized by hyperglycemia resulting from defects in insulin secretion, insulin action, or both. The long-term manifestation of diabetes can result in the development of some microvascular complications including neuropathy, nephropathy, and retinopathy and macrovascular complications including heart disease, stroke, and peripheral vascular disease, which can lead to ulcers, gangrene, and amputation (2). Even though the currently available drugs (insulin, sulfonylureas, biguanides, and thiazolidinediones) may be valuable in the management of diabetes, these drugs are usually accompanied by considerable side effects such as hypoglycemia, drug resis- tance, edema, and weight gain (3). Several species of plants have demonstrated potential for treatment of diabetes with lesser or no side effects (4). It is reported that about 800 plants may possess antidiabetic properties (5). Bioflavonoids are well known for their multidirectional biologic activities including antidiabetic effects. Numerous studies have already demonstrated the hypoglycemic effects of flavonoids in different experimental models and treatments. Flavonoids can act per se as insulin secretagogue or insulin mimetic agents, probably by influencing the pleiotropic mechanisms, to attenuate the diabetic complications. Flavonoids have been found to stimulate glucose uptake in peripheral tissues and regulate the activity and/or expression of the rate limiting enzymes involved in carbohydrate

Copyright ( ) 2014, Iranian Red Crescent Medical Journal; Published by Kowsar. This is an open-access article distributed under the terms of the Creative Commons Attribution-NonCommercial 4.0 International License (http://creativecommons.org/licenses/by-nc/4.0/) which permits copy and redistribute the material just in noncommercial usages, provided the original work is properly cited. 
metabolism pathway (6). Biochanin A, an isoflavone in the class of phytochemicals existing in red clover, cabbage, and alfalfa, has an inhibitory effect on benzo (a) pyrene metabolism (7) and prevents N-nitro-N-methylurea-induced mammary tumors in rats (8). It also exhibits various pharmacologic properties such as anti-inflammatory and anticarcinogenic effects. Present effort is to investigate the antidiabetic and antilipemic activity of biochanin A, and its effect on visfatin and other related biochemical parameters in streptozocin-induced diabetic rats. Visfatin is an adipocytokine that is highly expressed in visceral fat; it was originally isolated as a secreted factor that synergizes with IL-7 and stem cell factors to promote the growth of Bcell precursors (9). It is secreted by activated lymphocytes (9) monocytes, and neutrophils (10), stimulates the expression of IL-6 and IL-8 in amniotic cells (11), and prolongs neutrophil survival in clinical sepsis (10). Visfatin was named as such because of its much greater expression in visceral fat than in subcutaneous adipose tissue (12). Along with its insulin-mimetic effects, visfatin was as effective as insulin in inducing hyperglycemia in insulin deficient mice. It acts synergistically with insulin in increasing cellular uptake of glucose, stimulating glucose transfer to the muscle and adipose tissue, and prevents hepatic glucose production. Its insulin-like effects is mediated through direct bounding to and activation of insulin receptors without any change or competition with the insulin (13).

\section{Objectives}

In our study, we examined the effect of diabetic status on circulating visfatin in comparison with nondiabetic rats. We then assessed the effects of an insulin-mimetic flavonoid, biochanin A, in treatment of rats with type 2 diabetes mellitus and on circulating visfatin levels.

\section{Patients and Methods}

\subsection{Chemicals and Reagents}

Streptozocin and biochanin A were purchased from Sigma-Aldrich. All other chemicals used in this study were of analytical grade obtained from E Merck. Body weight was measured in the morning of the first and the last day of biochanin A administration by Balance: Sartorius TE64 (Germany). Serum concentrations of fasting blood glucose (FBG), triglycerides (TG), total cholesterol, and highdensity lipoprotein cholesterol (HDL-c) were measured enzymatically using commercial kits (Pars Azemoon, Tehran, Iran) with the aid of a spectrophotometer (JENWAY 6505 , Europe Union). Low-density lipoprotein cholesterol (LDL-c) was calculated by Friedewald formula: LDL-c $=$ Total cholesterol - [HDL-c + (TG/5)] (12). Serum alanine aminotransferase (ALT), aspartate aminotransferase (AST), and alkaline phosphatase (ALP) activities were measured by colorimetric diagnostic kit(ZIESTCHEM Company, Tehran, Iran). Glycosylated hemoglobin $\left(\mathrm{HbA}_{1} \mathrm{c}\right)$ was estimated by the method of cation exchange chromatography (Biosys- tems kit, Barcelona, Spain). The concentration of serum visfatin was determined by commercial enzyme immunoassay Kits (Bioassay technology laboratory, Shanghai, China) with the aid of an ELISA plate reader (ELX800TM, Bio-Tek, Winooski, VT, USA).

\subsection{Animals}

Male Wistar rats (weight, 160-180 g) were purchased from the Central Animal House, Tehran University of Medical Sciences, and were maintained in an air-conditioned room with the mean temperature of $25^{\circ} \mathrm{C} \pm 1^{\circ} \mathrm{C}$ and humidity of $55 \% \pm 5 \%$ with a 12 -hour light/12-hour dark cycle. All the rats were provided with commercially available rat normal pellet diet, which contained carbohydrate $60 \%(w / w)$, fat $2 \%(w / w)$, protein $17.5 \%(w / w)$, and fiber $8 \%$ $(w / w)$, and water ad libitum. Institutional Animals' Ethics Committee of Arak University of Medical Sciences, Arak, Iran, approved the study protocols.

\subsection{Induction and Selection of Diabetic Rats}

After an overnight fasting, $35 \mathrm{mg} / \mathrm{kg}$ of freshly prepared streptozocin (in citrate buffer with $\mathrm{pH}$ 4.5) was immediately injected intraperitoneally (IP) to induce diabetes. The respective control rats were given vehicle citrate buffer. The FBG was measured three days after streptozocin or vehicle injection. The rats with the FBG $>126 \mathrm{mg} / \mathrm{dL}$ were considered diabetic and selected for further studies.

\subsection{Experimental Design}

In this experimental study, 24 male Wistar rats were randomly allocated (simple randomization) to four groups (six rats in each group). One group was randomly selected and assigned as control group (group 1) and diabetes was induced in three other groups by administration of streptozocin ( $35 \mathrm{mg} / \mathrm{kg}$ ) IP. Biochanin A was suspended in $0.5 \% \mathrm{DMSO}$ and administrated orally once a day in the morning for 30 days. The studied groups and attributed treatments were as follow:

Group1: control (0.5\% DMSO)

Group 2: diabetic control (0.5\% DMSO)

Group 3: diabetic + biochanin A (10 mg/kg/day)

Group 4: diabetic + biochanin A (15 mg/kg/day)

The initial well as final body weight and FBG of all groups were recorded after 30 days in fasting condition. The animals were anesthetized using IP ketamine $(75 \mathrm{mg} / \mathrm{kg})$ and xylazine $(10 \mathrm{mg} / \mathrm{kg})$. Blood sample was collected by cardiac puncture and serum was separated immediately.

\subsection{Histopathologic Analysis}

On day 30, the pancreas tissues (five samples from each group) were removed and after washing with normal saline, they were stored in $10 \%$ formalin. The tissues embedded in paraffin and sectioned (Leica, Wetzlar, Germany), stained with hematoxylin and eosin, and subsequently examined under light microscope (Olympous, Tokyo, Japan). 
Azizi R et al.

\subsection{Statistical Analysis}

All the data were expressed as mean \pm standard error of three replicates for six rats in each group. Statistical analysis was performed using SPSS (version 19, SPSS Inc., Chicago, IL, USA). Normal assumption was examined using one-sample Kolmogorov-Smirnov test. One-way ANOVA was applied for determining differences between results of the studied groups. Post hoc test was used to compare the data. Pvalues $<0.05$ were considered statistically significant.

\section{Results}

Table 1 presents the effect of biochanin A on changes in FBG levels, body weight, and $\mathrm{HbA}_{1} \mathrm{c}$ in diabetic and control rats. Serum glucose level was measured in normal and diabetic rats on day zero and 30th day of oral administration of biochanin A. Three days after streptozocin injection, diabetic rats showed significant increase in the FBG in comparison to control group (day zero). Oral administration of biochanin A at doses of $10 \mathrm{mg} / \mathrm{kg}$ and $15 \mathrm{mg} / \mathrm{kg}$ for 30 days showed highly significant effects on FBG. Biochanin A with lower dose (10 $\mathrm{mg} / \mathrm{kg}$ ) was more effective on reducing FBG in comparison with the higher dose.

Diabetic rats showed decrease in body weight and administration of biochanin A at two different doses for 30 days improved body weight to almost normal limits. Between the two different doses, $10 \mathrm{mg} / \mathrm{kg}$ was more effective than $15 \mathrm{mg} / \mathrm{kg}$ when compared to the untreated diabetic rats. $\mathrm{HbA}_{1} \mathrm{c}$ increased significantly in diabetic rats and after treatment with biochanin $A$, the values were brought towards normal level. Oral administration of biochanin A at a dose of $10 \mathrm{mg} / \mathrm{kg}$ was more effective in decreasing HbA1c. However, the $\mathrm{HbA}_{1} \mathrm{c}$ was not completely reduced in comparison to normal rats.

The effects of biochanin A on lipid profile is shown in Table 2 . Serum HDL-c was significantly decreased and the level of TG was significantly increased in diabetic rats in comparison to group 1 rats. Total cholesterol and LDL-c increased in diabetic rats although it was insignificant. Oral administration of $10 \mathrm{mg} / \mathrm{kg}$ biochanin A restored the lipid profile to near normal limits. In this dose, total cholesterol, TG, and LDL-c were significantly decreased and the level of HDL-c was significantly increased in treated rats in comparison with the diabetic rats. There were not any significant changes in lipid profile in rats consuming 15-mg/kg biochanin A.

The activities of AST, ALT, and ALP were significantly increased in diabetic rats when compared to control group. Oral administration of biochanin A at a dose of $10 \mathrm{mg} /$ $\mathrm{kg}$ was significantly effective and the enzyme activities were brought back to near normal limits in diabetic rats. This dose was more effective than $15 \mathrm{mg} / \mathrm{kg}$ was (Table 3). Table 4 shows the effect of biochanin A on changes in visfatin concentration in normal and diabetic rats. Serum visfatin levels were elevated in diabetic rats. The mean serum level of visfatin in groups receiving biochanin A treatment was significantly decreased in comparison to untreated diabetic rats. Biochanin A was more effective at $15 \mathrm{mg} / \mathrm{kg}$ than at $10 \mathrm{mg} / \mathrm{kg}$.

The histopathologic assessment of pancreatic section showed that the islets in normal group displayed the complete structure and uniform arrangement (Figure 1A). As shown in Figure 1B, the number and size of pancreatic islets was decreased in diabetic group and sever pancreatic damage and degranulation of beta cells, vacuolation, and invasion of connective tissues were evident; some of them even showed apoptosis or necrosis. After treatment with biochanin A, the structure of islet was improved and histopathologic signs were ameliorated considerably. The cellular morphology of islet showed some degree of recovery. Amelioration and protective effects on pancreatic tissues was more in group 4 (Figure1D) than in group3 (Figure1C).

Table 1. Effect of Oral Administration of Biochanin A on Fasting Blood Glucose Levels, Body Weight, and Glycosylated Hemoglobin in Studied Rats a,b

\begin{tabular}{|c|c|c|c|c|c|}
\hline \multirow[t]{2}{*}{ Group } & \multicolumn{2}{|c|}{ FBG (mg/dL) } & \multicolumn{2}{|c|}{ Body weight (g) } & \multirow[t]{2}{*}{$\mathbf{H b A}_{1} \mathbf{c}(\%)$} \\
\hline & Day 0 & Day 30 & Day 0 & Day 30 & \\
\hline Normal & $68 \pm 3.4$ & $61 \pm 3.5$ & $189.3 \pm 3.2$ & $210.8 \pm 6.5$ & $5.19 \pm 0.22$ \\
\hline Diabetic Control & $225 \pm 3.8^{\mathrm{C}}$ & $295.1 \pm 14.2^{C}$ & $191.8 \pm 4.5$ & $161.5 \pm 6.7^{\mathrm{C}}$ & $8.26 \pm 0.44^{b}$ \\
\hline Diabetic + Biochanin A (10 mg/kg) & $215 \pm 12.6^{\mathrm{C}}$ & $139.8 \pm 9.3^{c, d}$ & $190.6 \pm 3.1$ & $200.5 \pm 2.6^{d}$ & $6.66 \pm 0.35^{d}$ \\
\hline Diabetic + Biochanin A (15 mg/kg) & $221 \pm 11.5^{\mathrm{C}}$ & $206 \pm 11^{c, d}$ & $188.6 \pm 5.1$ & $195.0 \pm 6.3^{d}$ & $7.11 \pm 0.31^{d}$ \\
\hline
\end{tabular}

a Each value is mean \pm SD of six rats in each group.

b Abbreviations: $\mathrm{FBG}$, fasting blood glucose; and $\mathrm{HbA}_{1} \mathrm{c}$, glycosylated hemoglobin.

C $\mathrm{P}<0.05$ in comparison with normal rats.

$\mathrm{d}_{\mathrm{P}}<0.05$ in comparison with diabetic rats.

Table 2. Effect of Oral Administration of Biochanin A on Serum Lipids in Studied Rats a,b

\begin{tabular}{|c|c|c|c|c|}
\hline Groups & Total Cholesterol, mg/dL & TG, mg/dL & LDL-c, mg/dL & HDL-c Cholesterol, mg/dI \\
\hline Normal & $102.3 \pm 9.64$ & $84.33 \pm 1.75$ & $49.30 \pm 8.4$ & $36.17 \pm 2.48$ \\
\hline Diabetic Control & $106.5 \pm 4.6$ & $89.50 \pm 1.51^{\mathrm{C}}$ & $58.43 \pm 5.03$ & $30.17 \pm 1.47^{\mathrm{C}}$ \\
\hline Diabetic + Biochanin A (10 mg/kg) & $95.17 \pm 4.16^{\mathrm{d}}$ & $75.67 \pm 3.55^{d}$ & $41.36 \pm 4.3^{\mathrm{d}}$ & $38.67 \pm 0.81^{d}$ \\
\hline Diabetic + Biochanin A (15 mg/kg) & $111.17 \pm 5.8$ & $93.17 \pm 4.16$ & $59.70 \pm 7.1$ & $32.83 \pm 1.94$ \\
\hline
\end{tabular}

a Each value is mean \pm SD of 6 rats in each group.

b Abbreviations: TG, triglyceride; LDL-c, low-density lipoprotein cholesterol; and HDL-c, high-density lipoprotein.

c $\mathrm{P}<0.05$ in comparison with normal rats.

d $\mathrm{P}<0.05$ in comparison with diabetic rats 
Azizi R et al.

Table 3. Effect of Oral Administration of Biochanin A on Serum alanine aminotransferase, aspartate aminotransferase, and alkaline phosphatase in Studied Rats a,b

\begin{tabular}{|c|c|c|c|}
\hline Groups & AST, U/dL & ALT, U/dL & ALP, U/dL \\
\hline Normal & $131.33 \pm 5.00$ & $52.17 \pm 1.83$ & $147.0 \pm 6.35$ \\
\hline Diabetic Control & $200.0 \pm 6.7^{c}$ & $98.33 \pm 3.93^{c}$ & $188.0 \pm 3.28^{C}$ \\
\hline Diabetic + Biochanin A (10 mg/kg) & $151.33 \pm 5.04^{d}$ & $67.00 \pm 6.29 \mathrm{~d}$ & $174.0 \pm 3.68^{d}$ \\
\hline Diabetic + Biochanin A (15 mg/kg) & $176.67 \pm 7.3^{d}$ & $78.0 \pm 2.09^{d}$ & $183.6 \pm 4.36$ \\
\hline
\end{tabular}

$\mathrm{a}$ Each value is mean \pm SD of six rats in each group.

b Abbreviations: ALT; alanine aminotransferase, AST; aspartate aminotransferase, ALP; alkaline phosphatase.

C $\mathrm{P}<0.05$ in comparison with normal rats.

$\mathrm{d}_{\mathrm{P}<0.05}$ in comparison with diabetic rats.

\begin{tabular}{|c|c|}
\hline Groups & Serum Visfatin, mg/dL \\
\hline Normal & $188.63 \pm 23.6$ \\
\hline Diabetic Control & $302.17 \pm 19.4^{b}$ \\
\hline Diabetic + Biochanin A (10 mg/kg) & $249.00 \pm 35.49^{C}$ \\
\hline Diabetic + Biochanin A (15 mg/kg) & $161.33 \pm 13.07^{\mathrm{C}}$ \\
\hline
\end{tabular}

a Each value is mean \pm SD of 6 rats in each group.

$\mathrm{b}$ P $<0.05$ in comparison with normal rats.

C $\mathrm{P}<0.05$ in comparison with diabetic rats.
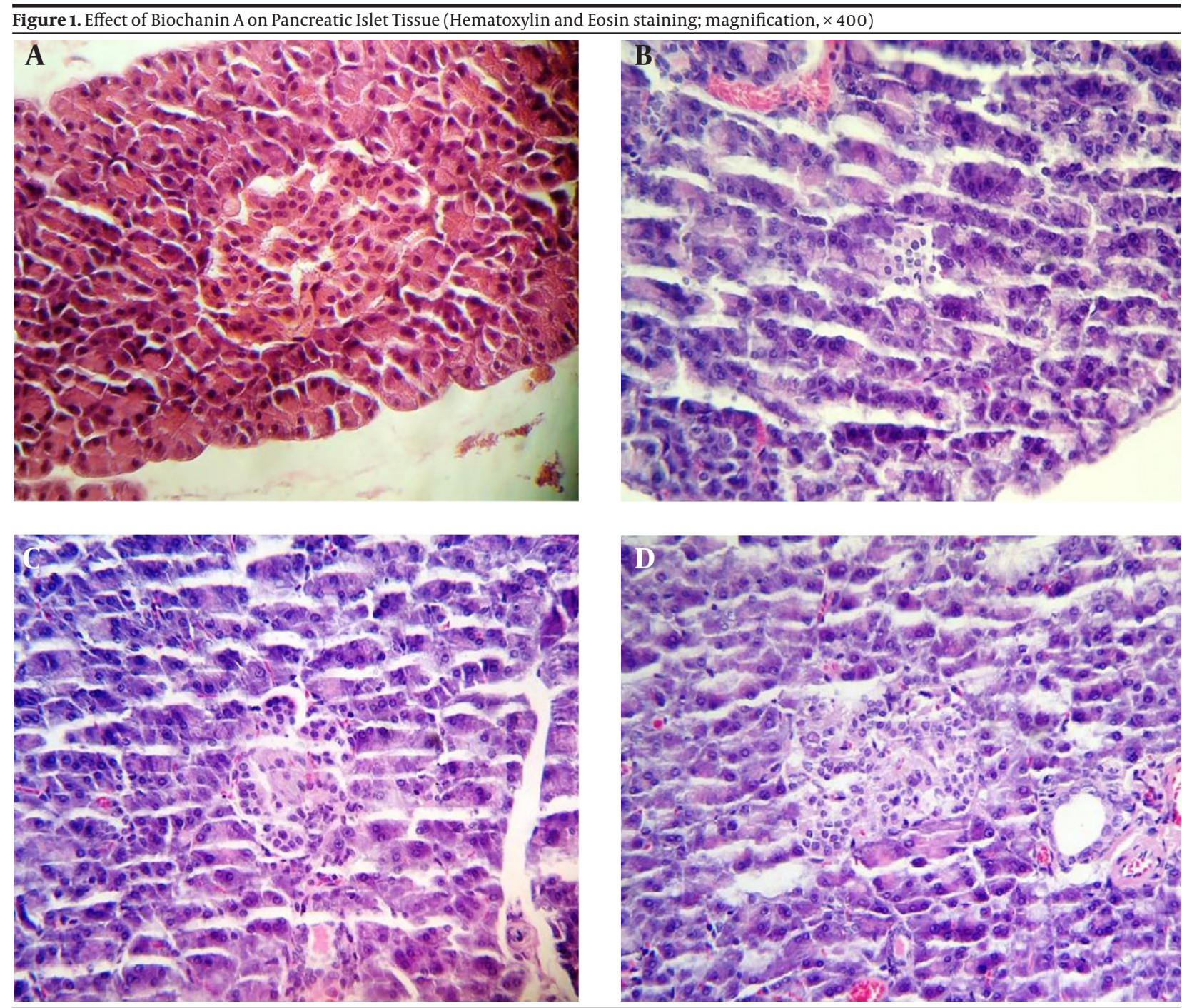

A, Normal rats. B, streptozocin-induced diabetic rats. C, streptozocin-induced diabetic rats treated with 10-mg/kg biochanin A. D, streptozocin-induced diabetic rats treated with $10-\mathrm{mg} / \mathrm{kg}$ biochanin A. 
Azizi R et al.

\section{Discussion}

In the present study, we observed significant effect of oral administration of biochanin A on FBG, body weight, $\mathrm{HbA}_{1} \mathrm{c}$, lipid profile, liver enzyme activities, and serum visfatin concentration in streptozocin-induced diabetic rats. Although high dose of streptozocin severely impairs insulin secretion mimicking type 1 diabetes, low dose of streptozocin destroys some population of pancreatic beta cells and has been known to induce a mild impairment of insulin secretion, which is similar to the feature of the later stage of type 2 diabetes (13). There was no significant variation in plasma insulin concentrations between diabetic and normal rats while FBG was significantly higher in diabetic rats; therefore, insulin resistance might have been developed in these animals. We used an animal model that would closely reflect the natural history and metabolic characteristics of human and it is further sensitive to pharmacological testing.

Our results showed that the increased levels of glucose in streptozocin-induced diabetic rats were significantly lowered, but the level of blood glucose in treatment groups was still higher than the normal group. Reduction in FBG by the administration of biochanin A suggested that it might increase the insulin secretion, which in turn raises glucose uptake by tissues. Biochanin A treatment effectually enhanced insulin secretion and a better glycemic control as well as antioxidant protection (14).

Brahmachari reported that flavonoids are naturallyoccurring phenolic compounds with a broad range of biologic activities and the beneficial effects of them have been studied in relation to diabetes through inhibition of intestinal alpha-glycosidase enzyme, their capacity to avoid glucose absorption, and/or to improve glucose tolerance (15). Biochanin A, a soy isoflavone, specifically has antidiabetic activity. The possible mechanism by which the biochanin A brings about hypoglycemic effect may be increasing the insulin level because of its protective effect on pancreatic beta cells and stimulation of insulin secretion from the remaining beta cells.

The streptozocin-induced diabetic rats significantly lost weight in comparison to control rats (16). Sever weight loss is a characteristic condition in diabetes; several studies have also reported a significant decrease in body weight of streptozocin-induced diabetic rats (17) owing to defect in glucose metabolism and excessive breakdown of tissue proteins (18). The present study, showed that after 30 days of oral administration of biochanin A, the rat health status were to some extent improved along with a good spirits. Simultaneously, the body weight significantly and gradually improved. Increase in the body weight of streptozocin-induced diabetic rats might be due to an improvement in insulin secretion and glycemic control. Increased insulin levels may contribute to the reduced hyperglycemia and improved body weight in treated diabetic rats (19). $\mathrm{HbA}_{1} \mathrm{c}$ levels were found to be significantly elevated in streptozocin-induced diabetic rats in comparison to the normal rats. Treatment with biochanin A decreased hyperglycemia and therefore, exhibited a significant reduction in the levels of $\mathrm{HbA}_{1} \mathrm{c}$.

Serum TG levels was significantly higher in the diabetic untreated rats in comparison to normal rats; on the other hand, although total cholesterol and LDL-c levels were higher, the difference was in significant. In addition, the levels of HDL-c were significantly lower in the former group. The abnormally high concentrations of serum lipids in the diabetic subjects are mainly due to the increase in the mobilization of free fatty acids from the peripheral fat depots since insulin inhibits the hormone-sensitive lipase. Insulin deficiency or insulin resistance may be responsible for dyslipidemia because insulin has an inhibitory action on HMG-CoA reductase, a key rate-limiting enzyme responsible for the metabolism of cholesterolrich LDL-c particle (20). An abnormality in lipid profile is one of the most common complications in diabetes and is associated with an increased risk of coronary heart disease $(21,22)$. Since lipid abnormalities accompanying with premature atherosclerosis are the major causes of cardiovascular disease in patients with diabetes, in addition to glycemic control, ideal treatment for diabetes, should have a favorable effect on lipid profile (23). After 30 days treatment with biochanin $\mathrm{A}(10 \mathrm{mg} / \mathrm{kg})$, a significant reduction in serum TG, total cholesterol, and LDL-c and a significant increase in the HDL-c level was observed. The glucose lowering action of the biochanin A might be due to consequent improved lipid metabolism apart from direct interaction with glucose homeostasis. The TG-lowering property could indirectly contribute to the overall antihyperglycemic activity through glucose-fatty acid cycle mechanism (24). According to this mechanism, increased supply of plasma TG per se could constitute a source of increased fatty acid availability and oxidation that can impair insulin action and hence, glucose metabolism and utilization that leads to development of hyperglycemia. Therefore, the reduction of TG following treatment with biochanin A would also facilitate the glucose oxidation and utilization and subsequently, the reduction of serum glucose.

The liver is regarded as the central organ of metabolism in the body with an important role in glucose and lipid metabolism (25). AST, ALT, and ALP are considered as liver toxicity markers and are used in the evaluation of hepatic disorders (26). Our result showed that serum AST, ALT, and ALP were increased in streptozocin-induced diabetic rats in comparison with normal rats. The increase in the activities of these serum enzymes indicated that diabetes might induce hepatic dysfunction and reflect active liver damage. Therefore, the increase in AST, ALT, and ALP activity may be mainly due to the leakage of these enzymes from the liver cytosol in to the blood serum, which gives an indication of the hepatotoxic effect of streptozocin (27). Oral administration of biochanin A, especially with a dose of $10 \mathrm{mg} / \mathrm{kg}$, significantly decreased these enzymes in comparison with the control diabetic rats. 
Little evidence is available for the effects of biochanin A polyphenols on visfatin expression in diabetic rats. There are reports showing an association between visfatin and metabolic syndrome (28). While elevation in visfatin level is observed in obese subjects, some researchers did not find any differences in this factor between those with metabolic syndrome and healthy controls (28-30). Since visfatin has been known as a proinflammatory cytokine (31), our finding that showed its elevation in diabetic rats were reasonable. Despite these finding about visfatin, its relationship with diabetes and metabolic syndrome still remains to be illuminated.

Our data also showed treatment of diabetic rats with biochanin A could lead to diminished visfatin level. Recent studies have indicated that visfatin has insulin mimetic effects in cultured adipocytes, myocytes, and hepatocytes and can reduce the plasma glucose levels in mice through binding and activating the insulin receptor (31). In addition, it is important to mention that visfatin acts as a phosphoribosyl transferase inside the cell and is involved in salvage pathway of $\mathrm{NAD}^{+}$biosynthesis. This regulation of cellular levels of $\mathrm{NAD}^{+}$affects the $\mathrm{NAD}^{+} / \mathrm{NADH}$ dependent enzymes (32).

According to histopathologic findings, damage in islet with pancreatic beta cells was ameliorated by administration of biochanin A. These findings demonstrated that biochanin A could exert the hypoglycemic and antilipemic effects through the mechanisms that might be associated with repairing pancreatic beta cells in diabetic rats.

\section{Acknowledgements}

We are grateful to Dr. Saeid Babaie and Dr. Maryam Baazm for technical supports.

\section{Financial Disclosure}

The authors declared that there was no conflict of interest with any financial organization regarding the material discussed in the manuscript.

\section{References}

1. Koyuturk M, Ozsoy-Sacan O, Bolkent S, Yanardag R. Effect of glurenorm on immunohistochemical changes in pancreatic beta cells of rats in experimental diabetes. Indian J Exp Biol. 2005;43(3):268-71.

2. Engelgau MM, Geiss LS, Saaddine JB, Boyle JP, Benjamin SM, Gregg EW, et al. The evolving diabetes burden in the United States. Ann Intern Med. 2004;140(11):945-50.

3. Tahrani AA, Piya MK, Kennedy A, Barnett AH. Glycaemic control in type 2 diabetes: targets and new therapies. Pharmacol Ther. 2010;125(2):328-61.

4. Zhang L, Yang J, Chen XQ, Zan K, Wen XD, Chen H, et al. Antidiabetic and antioxidant effects of extracts from Potentilla discolor Bunge on diabetic rats induced by high fat diet and streptozotocin. J Ethnopharmacol. 2010;132(2):518-24.

5. Grover JK, Yadav S, Vats V. Medicinal plants of India with antidiabetic potential. J Ethnopharmacol. 2002;81(1):81-100.

6. Brahmachari G. Bio-flavonoids with promising antidiabetic potentials: A critical survey. Opp challenge Scope Nat Prod Med Chem. 2011;2:187-212.
7. Lee YS, Seo JS, Chung HT, Jang JJ. Inhibitory effects of biochanin A on mouse lung tumor induced by benzo(a)pyrene.J Korean Med Sci.1991;6(4):325-8.

8. Yin $\mathrm{H}$, Ito $\mathrm{A}$, Bhattacharjee $\mathrm{D}$, Hoshi M. A comparative study on the protective effects of 17beta-estradiol, biochanin A and bi sphenol A on mammary gland differentiation and tumorigenesis in rats. Indian J Exp Biol. 2006;44(7):540-6.

9. Samal B, Sun Y, Stearns G, Xie C, Suggs S, McNiece I. Cloning and characterization of the cDNA encoding a novel human pre-B-cell colony-enhancing factor. Mol Cell Biol.1994;14(2):1431-7.

10. Jia SH, Li Y, Parodo J, Kapus A, Fan L, Rotstein OD, et al. Pre-B cell colony-enhancing factor inhibits neutrophil apoptosis in experimental inflammation and clinical sepsis. J Clin Invest. 2004;113(9):1318-27.

11. Ognjanovic S, Bryant-Greenwood GD. Pre-B-cell colony-enhancing factor, a novel cytokine of human fetal membranes. Am J Obstet Gynecol. 2002;187(4):1051-8

12. Uysal KT, Wiesbrock SM, Marino MW, Hotamisligil GS. Protection from obesity-induced insulin resistance in mice lacking TNFalpha function. Nature. 1997;389(6651):610-4.

13. Hajianfar H, Bahonar A, Entezari MH, Askari G, Yazdani M. Lipid Profiles and Serum Visfatin Concentrations in Patients with Type II Diabetes in Comparison with Healthy Controls. Int I Prev Med. 2012;3(5):326-31.

14. Lu MP, Wang R, Song X, Chibbar R, Wang X, Wu L, et al. Dietary soy isoflavones increase insulin secretion and prevent the development of diabetic cataracts in streptozotocin-induced diabetic rats. Nutr Res. 2008;28(7):464-71.

15. Fukuhara A, Matsuda M, Nishizawa M, Segawa K, Tanaka M, Kishimoto K, et al. Visfatin: a protein secreted by visceral fat that mimics the effects of insulin. Science. 2005;307(5708):426-30.

16. Kumar V, Ahmed D, Gupta PS, Anwar F, Mujeeb M. Anti-diabetic anti-oxidant and anti-hyperlipidemic activities of Melastoma malabathricum Linn. leaves in streptozotocin induced diabetic rats. BMC Complement Altern Med. 2013;13:222.

17. Kalaiarasi P, Pugalendi KV. Antihyperglycemic effect of 18 betaglycyrrhetinic acid, aglycone of glycyrrhizin, on streptozotocindiabetic rats. Eur J Pharmacol. 2009;606(1-3):269-73.

18. Sezik E, Aslan M, Yesilada E, Ito S. Hypoglycaemic activity of Gentiana olivieri and isolation of the active constituent through bioassay-directed fractionation techniques. Life Sci. 2005;76(11):1223-38.

19. Harini R, Ezhumalai M, Pugalendi KV. Antihyperglycemic effect of biochanin A, a soy isoflavone, on streptozotocin-diabetic rats. EurJ Pharmacol. 2012;676(1-3):89-94.

20. Guoyan J. Practical diabetes mellitus. Ppl Med Publ Hse. 1992:51-69.

21. Murali B, Upadhyaya UM, Goyal RK. Effect of chronic treatment with Enicostemma littorale in non-insulin-dependent diabetic (NIDDM) rats. Jthnopharmacol. 2002;81(2):199-204

22. Maghrani M, Lemhadri A, Zeggwagh NA, El Amraoui M, Halou $\mathrm{M}$, Jouad $\mathrm{H}$, et al. Effects of an aqueous extract of Triticum repens on lipid metabolism in normal and recent-onset diabetic rats. Ethnopharmacol. 2004;90(2-3):331-7.

23. Kesari AN, Kesari S, Singh SK, Gupta RK, Watal G. Studies on the glycemic and lipidemic effect of Murraya koenigii in experimental animals. J Ethnopharmacol. 2007;112(2):305-11.

24. Hue L, Taegtmeyer H. The Randle cycle revisited: a new head for an old hat. Am J Physiol Endocrinol Metab. 2009;297(3):E578-91.

25. Coppola A, Marfella R, Coppola L, Tagliamonte E, Fontana D, Liguori E, et al. Effect of weight loss on coronary circulation and adiponectin levels in obese women. Int J Cardiol. 2009;134(3):414-6.

26. Badole SL, Bodhankar SL. Antidiabetic activity of cycloart-23-ene3beta, 25-diol (B2) isolated from Pongamia pinnata (L. Pierre) in streptozotocin-nicotinamide induced diabetic mice. Eur J Pharmacol. 2010;632(1-3):103-9.

27. Eliza J, Daisy P, Ignacimuthu S, Duraipandiyan V. Antidiabetic and antilipidemic effect of eremanthin from Costus speciosus (Koen.)Sm., in STZ-induced diabetic rats. Chem Biol Interact. 2009;182(1):67-72.

28. Filippatos TD, Derdemezis CS, Kiortsis DN, Tselepis AD, Elisaf MS Increased plasma levels of visfatin/pre-B cell colony-enhancing factor in obese and overweight patients with metabolic syndrome. J Endocrinol Invest. 2007;30(4):323-6.

29. Pan HY, Guo L, Li Q. Changes of serum omentin-1 levels in norma 
Azizi R et al.

subjects and in patients with impaired glucose regulation and with newly diagnosed and untreated type 2 diabetes. Diabetes Res Clin Pract. 2010;88(1):29-33.

30. Chen CC, Li TC, Li CI, Liu CS, Lin WY, Wu MT, et al. The relationship between visfatin levels and anthropometric and metabolic parameters: association with cholesterol levels in women. Metabolism. 2007;56(9):1216-20.
31. Wang P, Xu TY, Guan YF, Su DF, Fan GR, Miao CY. Perivascular adipose tissue-derived visfatin is a vascular smooth muscle cell growth factor: role of nicotinamide mononucleotide. Cardiovasc Res. 2009;81(2):370-80.

32. Manolescu B, Stoian I, Atanasiu V, Busu C, Lupescu O. Review article: The role of adipose tissue in uraemia-related insulin resistance. Nephrology (Carlton). 2008;13(7):622-8. 